\title{
HUBUNGAN GLASGOW COMA SCALE DENGAN GLASGOW OUTCOME SCALE BERDASARKAN LAMA WAKTU TUNGGU OPERASI PADA PASIEN PERDARAHAN EPIDURAL
}

\author{
Ewi Astuti ${ }^{1}$, Syaiful Saanin ${ }^{1}$, Edison $^{2}$
}

\begin{abstract}
Abstrak
Cedera kepala merupakan penyebab kematian terbanyak dari keseluruhan angka kematian yang diakibatkan trauma. Epidural Hematoma (EDH) merupakan jenis yang paling banyak menjadi perhatian para klinisi dan peneliti karena frekwensi kejadiannya yang tinggi. Operasi EDH dianjurkan dilakukan sesegera mungkin setelah diagnosis ditegakkan. Operasi yang dilakukan sebelum waktu 4 jam, memberikan hasil perbaikan yang bermakna. Glasgow Coma Scale (GCS) dan waktu prehospital merupakan faktor terbesar yang mempengaruhi prognosa penderita EDH. Penilaian outcome suatu tindakan operasi dapat dinilai dengan Glassgow outcome scale (GOS). Penelitian ini bertujuan untuk menilai hubungan GSC dengan GOS berdasarkan lama waktu tunggu operasi pada pasien EDH di Instalasi Gawat Darurat RSUP Dr.M.Djamil Padang. Pada sampel dilakukan penilaian GCS dan GOS. Dari 10 sampel penelitian didapatkan penderita dengan jenis kelamin terbanyak laki-laki (60\%), usia tertinggi 35-45 tahun (60\%), GCS awal 9-12 (70\%), lama waktu tunggu terbanyak > 4 jam (80\%), skor GOS terbanyak adalah 4 (80\%). Tidak terdapat hubungan yang bermakna antara GCS saat awal masuk dengan nilai GOS $(p>0,05)$, tetapi terdapat hubungan yang bermakna antara lama waktu tunggu setelah cedera kepala sampai dilakukan operasi dengan GOS $(p<0,05)$.
\end{abstract}

Kata Kunci: Epidural hematoma, GCS, GOS, waktu tunggu operasi

\begin{abstract}
Head injury becomes the major cause of death in trauma. Epidural Haematoma (EDH) has become the major concern for the clinicians due to its high incidence. Surgical treatment was recommended to be done as soon as possible (less than 4 hours is suggested) after it was diagnosed to improve patient's outcome. Glasgow Coma Scale (GCS) and time interval are the most influencing factors of EDH patiens prognosis. Glassgow outcome scale (GOS) can be used to assess the outcomes of surgical treatment. This study aimed to assess the correlation between GCS and GOS of patients based on pre-operating time interval in Emergency installation of Dr.M.Djamil General Hospital - Padang. The GCS and GOS of the samples were then assessed. Of 10 samples included, we found that the highest frequency of the sample groups were male (60\%), with 35-45 years old in age group (60\%), the GCS of initial entry was mostly 9-12 (70\%), pre-operating time interval $>4$ hours (80\%), GOS group was 4 (80\%). There was no significant correlation between initial entry of GCS and GOS, but there was a significant correlation between preoperating time interval and GOS.
\end{abstract}

Key words: Epidural haematoma, GCS, GOS, pre-operating time interval.

Afiliasi Penulis: 1. Bagian IImu Bedah Fakultas Kedokteran Universitas Andalas/RSUP dr. M. Djamil Padang, 2. Bagian IImu Kesehatan Masyarakat FK Unand. Korespondensi: Ewi Astuti, email: astuti_ewi@yahoo.com, HP: 08126723532 


\section{PENDAHULUAN}

Cedera kepala adalah suatu keadaan non-kongenital dan non-degeneratif yang terjadi pada otak yang disebabkan oleh energi mekanik dari luar yang menyebabkan penurunan kognitif, fisik, dan fungsi psikososial yang bersifat sementara atau permanen dan dapat disertai penurunan kesadaran atau tidak. Cedera kepala dapat melibatkan setiap komponen yang ada pada kepala, mulai dari bagian terluar (SCALP) hingga bagian terdalam (intrakranial). Setiap komponen yang terlibat memiliki kaitan yang erat dengan mekanisma trauma yang terjadi. ${ }^{1}$

Epidural hematom (EDH) merupakan kumpulan darah di antara duramater dan tabula interna akibat trauma. Sebagian besar EDH berlokasi di daerah temporoparietal (70$80 \%)$, sedangkan $10 \%$ EDH berlokasi di frontal maupun oksipital. Biasanya disertai dengan terjadi fraktur kranium (85-96\%) pada daerah yang sama. Perdarahan yang terjadi dikarenakan robeknya arteri meningea media atau cabang-cabangnya, namun kadang dapat juga berasal dari vena. Volume EDH biasanya stabil, dan mencapai volume maksimum hanya beberapa menit setelah trauma, tetapi pada 9\% penderita ditemukan progresivitas perdarahan sampai 24 jam pertama. ${ }^{2,3}$

Pada epidural hematom, perdarahan terjadi di antara tulang tengkorak dan duramater. Perdarahan ini lebih sering terjadi di daerah temporal bila salah satu cabang Arteri Meningea Media robek. Robekan ini sering terjadi bila terdapat fraktur tulang tengkorak di daerah yang bersangkutan. Hematom dapat pula terjadi di daerah frontal atau oksipital. ${ }^{2}$

Arteri meningea media di dalam tengkorak masuk melalui foramen spinosum dan berjalan antara durameter dan tulang di permukaan dan os temporale. Perdarahan yang terjadi menimbulkan hematom epidural dan desakan oleh hematoma dapat melepaskan durameter lebih lanjut dari tulang kepala sehingga hematom bertambah besar. ${ }^{1,2}$ Karena perdarahan ini berasal dari arteri, maka darah akan terpompa terus keluar hingga makin lama hematom makin besar.

Ketika kepala terbanting atau terbentur mungkin penderita pingsan sebentar dan segera sadar kembali. Dalam waktu beberapa jam, penderita akan merasakan nyeri kepala yang progresif, diikuti kesadaran yang berangsur menurun. Masa antara dua penurunan kesadaran ini selama penderita sadar setelah terjadi kecelakaan disebut lucid interval. Fenomena lucid interval terjadi karena cedera primer yang ringan pada epidural hematom. Sementara pada subdural hematoma cedera primernya hampir selalu berat atau epidural hematoma dengan trauma primer berat tidak akan mengalami lucid interval karena pasien langsung tidak sadarkan diri dan tidak pernah mengalami fase sadar. ${ }^{1,2}$

Epidural hematoma merupakan kasus yang paling emergensi di divisi bedah saraf karena progresivitasnya yang cepat karena durameter melekat erat pada sutura sehingga langsung mendesak ke parenkim otak menyebabkan mudah herniasi trans- dan infratentorial. Oleh karena itu setiap penderita dengan trauma kepala yang mengeluh nyeri kepala yang berlangsung lama dan progresif memberat, harus segera dirawat dan diperiksa dengan teliti. ${ }^{4,5}$

Dengan teknologi CT-Scan diagnosis EDH bisa ditegakkan dengan cepat dan akurat. Lokasi perdarahan dan perkiraan volume perdarahan juga dapat diperkirakan dengan tepat. Kelainan lain seperti hematoma 
subdural, perdarahan intraserebral, perdarahan intraventrikel, hidrosefalus, edema serebri, dan tumor, yang dapat mengakibatkan peningkatan TIK juga dapat dilihat dari CT-Scan. ${ }^{6,7,8}$ Gambaran EDH pada CT-Scan adalah lesi hiperdens berbentuk bikonveks. ${ }^{7,9}$

Tekanan intrakranial (TIK) adalah tekanan yang timbul karena adanya volume massa otak, cairan cerebrospinal (LCS), dan darah yang mensuplai otak dalam suatu ruang intrakranial yang tertutup. TIK ini bisa meningkat oleh karena adanya perdarahan intrakranial (EDH, SDH, kontusio otak, PSA, $\mathrm{ICH})$, edema otak, tumor otak, dan hidrosefalus. ${ }^{10,11}$

Akibat dari adanya peningkatan TIK akan menyebabkan terjadinya penurunan aliran darah ke otak sehingga timbul iskemia otak. Iskemia otak adalah suatu gangguan hemodinamik yang menyebabkan penurunan aliran darah otak sampai ke suatu tingkat yang menyebabkan kerusakan otak yang ireversibel. TIK dapat diukur dengan satuan $\mathrm{cmH}_{2} \mathrm{O}$ atau $\mathrm{mmHg}$, dan memiliki nilai normal 50 sampai $200 \mathrm{mmH}_{2} \mathrm{O}$ atau $5-20 \mathrm{mmHg}$. ${ }^{12,13}$

Hasil segera yang ingin dicapai dari operasi adalah kembalinya tekanan intrakranial ke dalam batas normal, kembalinya pergeseran garis tengah, kontrol pendarahan dan mencegah perdarahan ulang. ${ }^{6}$

Secara umum indikasi operasi pada hematoma intrakranial yaitu adanya massa hematoma kira-kira $40 \mathrm{cc}$, massa dengan pergeseran garis tengah lebih dari $5 \mathrm{~mm}^{14}, \mathrm{EDH}$ dan SDH ketebalan lebih dari $5 \mathrm{~mm}$ dan pergeseran garis tengah dengan GCS 8 atau kurang, kontusio cerebri dengan diameter $2 \mathrm{~cm}$ dengan efek massa yang jelas atau pergeseran garis tengah lebih dari $5 \mathrm{~mm}$, pasien-pasien yang menurun kesadarannya dikemudian waktu disertai berkembangnya tanda-tanda lokal dan peningkatan tekanan intrakranial lebih dari $25 \mathrm{mmHg}$.

Tindakan operasi untuk kasus EDH merupakan jenis tindakan yang efektif, dengan biaya yang relatif ringan serta memberikan manfaat yang besar. Pasien EDH yang dioperasi dalam waktu 4 jam pasca kejadian memberikan hasil perbaikan yang bermakna. ${ }^{14}$

Beberapa ahli bedah menganut pada four hour rules, hasil dari hal tersebut dipublikasikan di Fakultas Kedokteran Virginia, isinya adalah: ${ }^{15}$

1. Pasien-pasien yang dioperasi dalam waktu 4 jam trauma mempunyai angka mortalitas 30\%, dibandingkan dengan angka mortalitas $90 \%$ jika dioperasi dalam waktu lebih dari 4 jam.

2. Fungsional survival rate mencapai $65 \%$ dapat dicapai jika dioperasi dalam waktu 4 jam.

3. Faktor-faktor lain yang berhubungan adalah ICP pasca operasi ICP $<20 \mathrm{mmHg}$ mempunyai $79 \%$ pasien sembuh secara fungsional, pemeriksaan saraf inisial, umur bukan suatu faktor, gejala yang sangat menonjol ialah kesadaran menurun secara progresif. Pasien dengan kondisi seperti ini seringkali tampak memar di sekitar mata dan di belakang telinga. Sering juga tampak cairan yang keluar pada saluran hidung atau telinga. Pasien seperti ini harus diobservasi dengan teliti, setiap orang memiliki kumpulan gejala yang bermacam-macam akibat dari cedera kepala. Banyak gejala yang muncul bersamaan pada saat terjadi cedera 
kepala.

Pemeriksaan pada penderita-penderita cedera kepala hendaklah ditekankan pada pemeriksaan neurologi seperti menilai kesadaran penderita dengan menggunakan Glasgow Coma Scale, diameter kedua pupil, defisit motorik, dan tanda-tanda peningkatan tekanan intrakranial. ${ }^{16}$

Glasgow Coma Scale (GCS) diciptakan oleh Jennett dan Teasdale pada tahun 1974. Sejak itu GCS merupakan tolok ukur klinis yang digunakan untuk menilai beratnya cedera kepala. Pemeriksaan GCS seharusnya telah dilakukan pada penderita-penderita pada awal cedera kepala terutama sebelum mendapat obat-obat paralitik dan sebelum intubasi; skor ini disebut skor awal GCS, dimana mempunyai pengaruh yang kuat terhadap kesempatan hidup dan penyembuhan. ${ }^{17}$

Skor GCS 8 atau kurang diterima sebagai derajat cedera kepala berat atau koma, skor 913 cedera kepala sedang dan skor 14-15 cedera kepala ringan. Derajat kesadaran tampaknya mempunyai pengaruh yang kuat terhadap kesempatan hidup dan penyembuhan. GCS juga merupakan faktor prediksi yang kuat dalam menentukan prognosis dimana suatu skor GCS yang rendah pada awal cedera berhubungan dengan prognosis yang buruk. ${ }^{18}$

Menurut Sastrodiningrat yang mengutip pendapat Jennet dkk, melaporkan bahwa $82 \%$ dari penderita-penderita dengan skor GCS 11 atau lebih, dalam waktu 24 jam setelah cedera mempunyai good outcome atau moderately disabled dan hanya $12 \%$ yang meninggal atau mendapat severe disability. Outcome secara progresif akan menurun bila skor awal GCS menurun. Di antara penderita-penderita dengan skor awal GCS 3 atau 4 dalam 24 jam pertama setelah cedera hanya $7 \%$ yang mendapat good outcome atau moderate disability. Di antara penderita-penderita dengan skor GCS 3 pada waktu masuk dirawat, 87\% akan meninggal. Kehilangan kesadaran yang lama, dalam banyak hal tidak prediktif terhadap outcome yang buruk. ${ }^{9,17,19}$

Aarabi dkk, mendapatkan adanya hubungan yang kuat antara GCS awal dengan outcome pada perdarahan epidural. Demikian juga Phillips Taussky dkk menyimpulkan bahwa GCS awal pasien merupakan faktor penting dalam memperkirakan outcome pasien dengan perdarahan epidural. ${ }^{3,17}$

Glasgow Outcome Scale dikembangkan pertama kali oleh Jennet dan Bond pada tahun 1975. Mereka mengembangkan GOS dengan tujuan mengklasifikasi bermacam-macam kondisi outcome yang terdapat pada pasien pasca cedera kepala. Seperti yang telah disebutkan sebelumnya GOS terdiri 5 kategori. Kategori GOS mulai dari Good Recovery (GOS 5) hingga Death (GOS 1). 5,17

\section{METODE}

Penelitian ini merupakan studi observasional dengan desain longitudinal study untuk menilai hubungan Glassgow Coma Scale dengan Glassgow Outcome Scale berdasarkan lama waktu tunggu operasi pada pasien perdarahan epidural. Penelitian dilaksanakan di Instalasi Gawat Darurat Rumah Sakit Dr. M. Djamil Padang. Waktu penelitian dilaksanakan selama tiga bulan mulai Maret sampai dengan Mei 2015.

Pada penelitian ini didapatkan jumlah sampel sebanyak 10 orang penderita EDH, dimana sampel terdiri dari 6 orang laki-laki dan 4 orang perempuan. Pengambilan sampel pada penelitian ini dilakukan secara total sampling. 
Pada subyek penelitian awalnya dilakukan penilaian GCS saat masuk. Diagnosa EDH ditegakkan dengan bantuan CT-Scan. Setelah subyek penelitian memahami dan menyetujui tindakan yang akan dilakukan serta telah mengisi formulir persetujuan, maka dilakukan tindakan operasi, setelah sebelumnya dicatat berapa lama waktu tunggu mulai dari terjadi cedera hingga dilakukannya tindakan operasi. Kemudian dilakukan penilaian terhadap GOS saat subyek pulang.

Data yang terkumpul kemudian diolah, dianalisis, dan disajikan dengan menggunakan program komputer. Batas kemaknaan $p \leq 0,05$. Untuk menilai hubungan Glassgow Coma Scale awal dan jarak waktu tunggu operasi pada pasien perdarahan epidural dengan Glasgow Outcome Scale, data dianalisa dengan $t$ Test.

\section{HASIL DAN PEMBAHASAN}

Telah dilakukan penelitian dari bulan Februari sampai April 2015, dijumpai 10 pasien dengan cedera kepala yang dilakukan tindakan operasi setelah didiagnosa dengan perdarahan epidural post traumatik dengan bantuan CT-Scan. Pasien dengan cedera pada organ utama lainnya tidak dimasukkan dalam penelitian ini. Dari 10 orang pasien didapatkan 6 orang berjenis kelamin laki-laki dan 4 orang berjenis perempuan. Data demografi subyek yang mengikuti penelitian ini ditampilkan pada tabel.

Pengaruh dari GCS saat awal masuk dan jarak waktu antara cedera kepala dan operasi terhadap mortalitas dan morbiditas dievaluasi. Data kemudian dievaluasi dan nilai $p<0,05$ dianggap secara statistik bermakna. Dari 10 pasien perdarahan epidural yang dilakukan tindakan operasi, 8 pasien memperlihatkan pemulihan yang baik dan 2 pasien sedang dalam pemulihan atau pemulihan sedang. Tidak ada yang berat dan termasuk vegetatif state.

Tabel 1. Karakteristik Responden Menurut Umur dan Jenis Kelamin

\begin{tabular}{lll}
$\begin{array}{l}\text { Karakteristik responden } \\
\text { berdasar umur dan } \\
\text { jenis kelamin }\end{array}$ & F & $\%$ \\
\hline Umur & & \\
$15-35$ & 3 & 30 \\
$36-45$ & 6 & 60 \\
$46-65$ & 1 & 10 \\
Jenis Kelamin & & \\
laki-laki & 6 & 60 \\
Perempuan & 4 & 40 \\
\hline
\end{tabular}

Tabel 2. Karakteristik Responden Menurut GCS Awal

\begin{tabular}{ccc}
\hline GCS Awal & F & $\%$ \\
\hline $3-8$ & 0 & 0 \\
$9-12$ & 7 & 70 \\
$13-15$ & 3 & 30 \\
Total & 10 & 100 \\
\hline
\end{tabular}

Tabel 3. Karakteristik Responden Menurut Waktu Tunggu Operasi dan GOS Pulang

\begin{tabular}{lll}
\hline $\begin{array}{l}\text { Karakteristik responden } \\
\text { menurut waktu tunggu dan } \\
\text { GOS pulang }\end{array}$ & F & $\%$ \\
\hline Lama waktu tunggu & 2 & 20 \\
$\leq 4$ jam & 8 & 80 \\
$>4$ jam & & \\
GOS pulang & 2 & 20 \\
3 & 8 & 80 \\
4
\end{tabular}

Tabel 4. Hubungan Antara GCS Awal dengan GOS

\begin{tabular}{ccc}
\hline GCS Awal & GOS & Korelasi Spearman \\
\hline 9 & 4 & \\
9 & 4 & $\mathrm{r}=0,247$ \\
9 & 4 & $\mathrm{p}=0,444$ \\
10 & 4 & $\mathrm{n}=10$ \\
14 & 4 & \\
14 & 4 & \\
11 & 4 & \\
14 & 4 & \\
10 & 3 & \\
9 & 3 & \\
\hline
\end{tabular}


Tabel 5. Hubungan Antara Lama Waktu Tunggu dengan GOS

\begin{tabular}{ccc}
\hline $\begin{array}{c}\text { Lama Waktu } \\
\text { Tunggu (Jam) }\end{array}$ & GOS & Korelasi Spearman \\
\hline 3 & 4 & \\
5 & 4 & $\mathrm{r}=0,703$ \\
5 & 4 & $\mathrm{p}=0,023$ \\
8 & 4 & $\mathrm{n}=10$ \\
12 & 4 & \\
6 & 4 & \\
2 & 4 & \\
6 & 4 & \\
14 & 3 & \\
14 & 3 & \\
\hline
\end{tabular}

Pada penelitian ini didapatkan kasus penderita perdarahan epidural yang dilakukan tindakan operasi sebanyak 10 orang, dengan penderita berjenis kelamin laki-laki sebanyak 6 orang dan berjenis perempuan sebanyak 4 orang. Diseluruh dunia, laki-laki lebih sering dijumpai mengalami cedera kepala dibanding dengan perempuan pada tiap kelompok usia. Dari data demografi ke 10 sampel penelitian, didapatkan kelompok usia terbanyak yang menderita perdarahan epidural yang dilakukan tindakan operasi adalah kelompok usia 35-45 tahun, hal ini sesuai dengan data di Indonesia, bahwa sebagian besar (70\%) korban kecelakaan lalu lintas adalah pengendara sepeda motor dengan golongan umur 15-55 tahun, dan cedera kepala merupakan urutan pertama dari semua jenis trauma yang di alami korban kecelakaan.

Tabel 6. Hubungan Antara GCS Awal dengan GOS Berdasarkan Lama Waktu Tunggu Operasi

\begin{tabular}{cllllll}
\hline \multirow{2}{*}{ GCS } & Waktu & \multicolumn{7}{c}{ GOS } \\
\cline { 3 - 7 } & Tunggu & $\mathbf{1}$ & $\mathbf{2}$ & $\mathbf{3}$ & $\mathbf{4}$ & $\mathbf{5}$ \\
\hline \multirow{2}{*}{$3-8$} & $\leq 4$ jam & 0 & 0 & 0 & 0 & 0 \\
& $>4$ jam & 0 & 0 & 0 & 0 & 0 \\
\multirow{3}{*}{$9-13$} & $\leq 4$ jam & 0 & 0 & 0 & 2 & 0 \\
& $>4$ jam & 0 & 0 & 1 & 4 & 0 \\
\multirow{3}{*}{$14-15$} & $\leq 4$ jam & 0 & 0 & 0 & 0 & 0 \\
& $>4$ jam & 0 & 0 & 0 & 3 & 0 \\
\hline
\end{tabular}

Berdasarkan distribusi GCS saat awal masuk, didapatkan penderita perdarahan epidural dengan cedera kepala sedang (GCS 913) sebanyak $70 \%$, cedera kepala ringan dengan GCS 14 - 15 sebanyak $30 \%$ dan tidak ada ditemukan pasien dengan cedera kepala berat.

Berdasarkan distribusi waktu tunggu, didapatkan 8 sampel (80\%) dengan waktu tunggu $>4$ jam. Dari literatur disimpulkan bahwa jarak waktu antara cedera kepala dan tindakan operasi merupakan faktor terapeutik terpenting pada perdarahan epidural. Penderita-penderita yang dilakukan tindakan operasi dalam waktu 4 jam sejak kejadian trauma memiliki tingkat mortalitas $30 \%$, sedangkan penderita-penderita yang dilakukan tindakan operasi lebih dari 4 jam setelah kejadian trauma memiliki tingkat mortalitas $90 \% .^{9,14,19}$

Dari perhitungan uji korelasi Spearman terhadap hubungan antara GCS awal pasien dengan GOS pasien saat pulang didapatkan hubungan positif yang lemah dan tidak bermakna. Walaupun demikian, dari penelitian ini terlihat bahwa penderita perdarahan epidural dengan GCS saat awal masuk yang tinggi mempunyai prognosis lebih baik dibanding dengan pasien dengan GCS awal masuk rendah. GCS saat awal masuk mempunyai korelasi dengan tingkat mortalitas pada penderita cedera kepala. Masalah yang dihadapi bila menggunakan GCS saat awal masuk sebagai predictor prognosis adalah seberapa tepat penilaian GCS saat awal masuk dan kurang akuratnya untuk memprediksi prognosis apabila GCS saat awal masuk rendah. ${ }^{9,14}$ Sehingga dari penelitian ini dapat disimpulkan bahwa tidak terdapat hubungan yang bermakna antara GCS awal masuk dengan GOS berdasarkan lama waktu tunggu operasi pada pasien perdarahan epidural.

Pada penelitian ini didapatkan koefisien korelasi antara jarak waktu operasi dengan nilai GOS adalah -0,703 dengan nilai p 0,023 
yang berarti antara jarak waktu operasi dan nilai GOS memiliki hubungan negatif yang kuat dan memiliki hubungan yang bermakna. Semakin cepat pasien perdarahan epidural diberi tindakan operasi, maka prognosis semakin baik. Namun hubungan antar variabel GCS awal dengan GOS berdasarkan lama waktu tunggu operasi tidak bisa diuji statistik dikarenakan kurangnya sampel penelitian.

\section{DAFTAR RUJUKAN}

1. Selladurai B, Reilly P. Apidemiology of acute Head Injury. In: initial Management of Head Injury, A Comprehensive Guide. China: Mc Graw Hill Medical. 2007.

2. Valadka Ab, Narayan RK. Injury to the Cranium. In: Feliciani DV, Moore EE, Mattox KL. Editors. Trauma 3rd ed. Connecticut Appleton and Lange; 1999. P 267-70, 273-5.

3. Aarabi B, Mehta R, Eisenbergh HM Management of Severe Head Injury. In: Moore AJ, Newell DW. Editor. Neurosurgery: London, 2005: p $369-78$.

4. Hafid A, Epidural Hematoma, Buku Ajar IImu Bedah, edisi kedua, Jong W.D. EGC, Jakarta, 2004. p.818-819.

5. Markam S, Trauma Kapitis, Kapita Selekta Neurologi, Edisi kedua, Harsono, Gajah Mada University Press, Yogyakarta, 2005, p.314

6. Iskandar J. Cedera Kepala. Jakarta: Buana Ilmu Populer Kelompok IImu Gramedia: 2004

7. Perron AD. How to Read a Head CT scan. In: injury to the Bone and Organs. New York. Mc Graw Hill, 2008: chp 69: 356- 58

8. Bullock MR, Chesnut R, Ghajar J, Gordon D, Hartl R, Newell DW, et al. Surgical management of Acute Epidural Hematomas. Neurosurgery, 2006. 58 (3 Suppl): S7-15.

9. Head Injury. (Internet) 2013 (dikutip 25 Maret 2013)

Dari:

\section{SIMPULAN}

Tidak terdapat hubungan yang bermakna antara GCS saat awal masuk dengan nilai GOS, dan terdapat hubungan yang bermakna antara lama waktu tunggu setelah cedera kepala sampai dilakukan operasi dengan nilai GOS yang bersifat positif sangat kuat. Interval waktu setelah cedera kepala sampai dilakukan operasi diperkirakan dapat digunakan sebagai prediktor prognosis penderita perdarahan epidural.

http://search.medscape.com/referencesearch?newSearchRefHome=|\&queryText=he ad+injury

10. Ullman JS, Sin Anthony. Epidural hemorrhage. In: Nosco MG, Talavera F editors. Traumatic brain injury. May 2006. Available from URL: http://www.

emedicine.medscape.com/article/248840overview

11. Rosner MJ. Pathophysiology and management of intracranial pressure monitoring. In: Andrew BT. Editor. Neurosurgical intensive care. 3 rd ed. New York: Mc Graw-Hill. 2002. p.122.

12. Moulton R J, Pitts L H. Head Injury and Intracranial Hypertension. In: Principles of Critical Care, ed.3. USA: McGraw Hill, 2005. p: 1395-1407.

13. Bruce DA, Schut L, Bruno LA, Wood JH, Sutton LN. Outcome following severe head injury in children. J Neurosurg 1978; 48(5): $679-88$.

14. Naroyon Rk. Head injury, in grsmon RG, Hamilton W. Principles of Neurosurgeon. New York. Raven Press: 1991

15. Scolotta TA, Scheider JJ. Emergency Management of Trauma 2nd Ed. Mc Graw Hill. 2001; 73-84.

16. Dahnert W, MD, Brain Disorders, Radiology Review Manual, second edition, Williams \& Wilkins, Arizona, 1993, 117-178 
17. Sastrodiningrat AG. Memahami Faktor-Faktor yang Mempengaruhi Prognosa Cedera Kepala Berat. Majalah Kedokteran Nusantara 2006, Vol 39 No.3

18. Jennet B, Snoek J, Bond MR, Brooks N. Disability after severe head injury: observation on the use of the Glasgow Outcome scale. J Neurol, Neurosurg, Psychiat 1981; 44(4): 285-93.
19. Manley et al. Hypotension, Hypoxia, and head injury: frequency, duration and consequences. Arch Surg 2001. 136(10): 1118-2. 